\title{
Breed differences in humoral and cellular responses of lambs to experimental infection with the gastrointestinal nematode Teladorsagia circumcincta
}

\author{
Albin Mostaque Ahmed ${ }^{1,2+}$, Simone Rocco Sebastiano ${ }^{1,2+}$, Torres Sweeney ${ }^{1}$, James Patrick Hanrahan², \\ Assumpta Glynn², Orla Mary Keane ${ }^{3}$, Anindya Mukhopadhya', Kevin Thornton ${ }^{1}$ and Barbara Good²*
}

\begin{abstract}
While Texel lambs have increased resistance to infection with the gastrointestinal nematode Teladorsagia circumcincta compared to Suffolk lambs, the underlying resistance mechanisms are still unknown. The aim of this study was to compare parasitological, humoral and cellular responses of Texel and Suffolk lambs over time following a single experimental infection with $T$. circumcincta. Gastrointestinal nematode free (but not naïve) lambs received a single oral dose of $3 \times 10^{4}$ infective $T$. circumcincta larvae. The variables examined included worm burden, mucosal and serum IgA, abomasal mast cells and eosinophils, haematological parameters and plasma pepsinogen. Texel lambs had significantly lower worm burden on day 14 and lower plasma pepsinogen concentration from day 14 onwards than Suffolks and their response in mucosal IgA to infection occurred earlier. The results from the study suggest that an earlier local IgA response in the Texel contributes to the resistant characteristics of the breed, while the increased level of plasma pepsinogen in the Suffolk lambs implies greater abomasal tissue damage arising from the nematode infection.
\end{abstract}

\section{Introduction}

Teladorsagia circumcincta is among the most important gastrointestinal nematode (GIN) species affecting sheep production in temperate regions [1,2]. GIN infection has a negative effect on reproductive performance, milk production, body weight, carcass quality and survival $[3,4]$. Extensive use of anthelmintics as a control strategy has resulted in the evolution of anthelmintic resistance in various nematode species [5]. This together with consumer concern over drug residues in animal products has promoted interest in the development of alternative methods of GIN control, such as genetic selection for increased host resistance to GIN. A number of studies have already identified established breeds that are relatively resistant to various GIN species [6-9]. In Ireland,

\footnotetext{
* Correspondence: barbara.good@teagasc.ie

${ }^{\dagger}$ Equal contributors

${ }^{2}$ Animal \& Grassland Research and Innovation Centre, Teagasc, Athenry, Co. Galway, Ireland

Full list of author information is available at the end of the article
}

the Texel breed is more resistant to GIN infection than the Suffolk [6]. Identification of physiological markers associated with resistance would facilitate the classification of resistance status of individuals and thus contribute to the development of rapid reliable markers for use in national sheep breeding programmes. Resistance to nematode infection can be manifest as a combination of impaired larval establishment, inhibition of larval development, reduced worm fecundity and/or accelerated worm expulsion [10,11]. Resistant animals may have more efficient mechanisms for affecting some or all of these physiological processes. While the only direct method of identification of resistant animals is to measure worm burden, this is not practical for use in breeding programmes, as it requires animals to be sacrificed [12]. Faecal egg count (FEC) is positively correlated with worm burden [13] and has been proposed and used as a marker of resistance to GIN $[14,15]$. However, there are various limitations to FEC data including variability due to host factors (age, gender, immune status and stress), 
parasite specific factors (variability in species composition, fecundity, developmental stage), environmental factors (nutrition, climate), sampling accuracy and precision [16-21].

It is hypothesised that physiological processes that determine host control of worm burden will vary between resistant and susceptible animals following GIN challenge. Previous data have suggested that resistance to GIN infection depends on the activation of an effective Th2 immune response which elicits a humoral immune response and results in the recruitment of eosinophils and mast cells to the gastrointestinal mucosa and the local production of IgA and IgE antibodies [22]. Pepsinogen concentration in blood plasma reflects the extent of abomasal tissue damage [23] and is elevated in Suffolk lambs naturally infected with GIN in comparison to Texel lambs [24].

The objective of this study was to identify physiological markers in blood or abomasal mucosa that differ between Suffolk and Texel lambs following artificial challenge with infective $T$. circumcincta larvae that may be indicators of resistance/susceptibility to $T$. circumcincta infection.

\section{Materials and methods Ethical approval}

All procedures described in this study were conducted under experimental license from the Irish Department of Health in accordance with the Cruelty to Animals Act 1876 and the European Communities (Amendments of the Cruelty to Animals Act 1976) Regulations, 2002 and 2005.

\section{Animals}

All lambs (32 Texel and 29 Suffolk) were sourced from the flock of purebred Suffolk and Texel sheep maintained at Athenry Research Centre [6]. Lambs of both the breeds were born indoors from a synchronised mating programme and then all the lambs were moved to the same pasture for a 6-week period. Lambs were weaned at about 6 weeks of age and moved indoors where they were maintained on a concentrate-based diet with free access to water for the remainder of the experiment. Upon housing, faecal sampling per rectum was attempted on all lambs, but sufficient material was obtained from only 36 individuals (16 Texel and 20 Suffolk). All lambs were then treated with Ivermectin (Oramec, Merial Animal Health Limited) according to the manufacturer's instructions and quarantined in a slatted pen for a period of $48 \mathrm{~h}$ prior to being penned as one group on straw. Information on age and live weight at housing together with the results from the faecal samples collected [25] at housing are summarised in Table 1. Five weeks post-housing and anthelmintic treatment, faecal samples were collected from all animals on 3 consecutive days to determine GIN infection status. Lambs with a positive FEC for "other" trichostrongyles $\left(\mathrm{FEC}_{\mathrm{OT}}\right)$, excluding Strongyloides papillosus, (two cases: 1 epg and 2 epg) or for S. papillosus (FEC SPAP 7 cases: epg ranged from 1 ( 5 cases) to 50 ( 2 cases) on any of these days were treated with Ivermectin (Noromectin Drench, Norbrook Laboratories Limited) according to the manufacturer's instructions and re-sampled to establish the GIN infection status; all were observed to be GIN negative. Approximately 1 week prior to administration of the challenge bolus, lambs were weighed and faecal sampled to confirm the GIN free status.

\section{Experimental infection}

At approximately 20 weeks of age ( 14 weeks post housing), the lambs were randomly assigned within breed, to one of 6 slaughter time points $(0,3,7,14,21$ or 35 days post-infection (pi)), with the restriction that members of a twin pair were not assigned to the same time point. The slaughter days were chosen based on the expected developmental stages of $T$. circumcincta in the sheep abomasum; day 3 and day 7 (L4 stage), day 14 (immature adult), days 21 and 35 (mature adult). Animals assigned to the day 0 time point (6 Texel and 4 Suffolk) did not receive an experimental challenge, while all other lambs ( 5 per breed per time point with an exception of 6 Texels for the day 35 time point) received a single oral dose of $3 \times 10^{4}$ infective $T$. circumcincta larvae (L3). Blood samples were collected into vacutainers with EDTA, lithium-heparin or no anticoagulant,

Table 1 Information ( \pm s.e.) on age, live weight and faecal egg counts for the experimental animals at housing

\begin{tabular}{|c|c|c|c|}
\hline Item & Suffolk & Texel & $P$ value \\
\hline No. of lambs & $29(20)^{\dagger}$ & $32(16)^{\dagger}$ & - \\
\hline Date of birth & 28 March & 29 March & - \\
\hline Age at housing (days) & $40.2 \pm 0.59$ & $39.2 \pm 0.56$ & $>0.2$ \\
\hline Live weight at housing $(\mathrm{kg})$ & $17.7 \pm 0.71$ & $17.7 \pm 0.68$ & $>0.9$ \\
\hline $\mathrm{FEC}_{\mathrm{OT}}$ (log scale) & $4.3 \pm 0.25(41)^{\ddagger}$ & $3.6 \pm 0.10(12)^{\ddagger}$ & $<0.01$ \\
\hline $\mathrm{FEC}_{\text {NEM }}$ (log scale) & $5.8 \pm 0.23(298)^{\ddagger}$ & $5.1 \pm 0.27(132)^{\ddagger}$ & $<0.05$ \\
\hline Live weight 1 week prior to challenge $(\mathrm{kg})$ & $46.2 \pm 1.51$ & $43.5 \pm 1.51$ & $>0.1$ \\
\hline
\end{tabular}

${ }^{\dagger}$ No. of lambs that yielded a faecal sample at housing.

${ }^{\ddagger}$ Back-transformed from mean value on $\log _{\mathrm{e}}$ scale. 
respectively, by jugular vene-puncture immediately prior to slaughter. Plasma was harvested following centrifugation at $2000 \mathrm{~g}$ for $5 \mathrm{~min}$ at $4{ }^{\circ} \mathrm{C}$ and stored at $-20{ }^{\circ} \mathrm{C}$ until use. Blood collected for serum antibody measurement was stored in a refrigerator overnight for clotting. Serum was extracted following centrifugation at $2000 \mathrm{~g}$ for $5 \mathrm{~min}$ and stored at $-20{ }^{\circ} \mathrm{C}$ until use. Faeces were collected per rectum on day 21 and $35 \mathrm{pi}$ and a $3 \mathrm{~g}$ aliquot was used to determine the FEC using the modified McMaster method [25]. Animals were slaughtered by electrical stunning followed immediately by exsanguination.

\section{Worm count}

The abomasum was recovered immediately after sacrifice and the contents recovered; the abomasum was then dissected along the greater curvature. A saline-digest technique was used to recover the worms from the abomasal mucosa [26]. Both contents and digest were washed through sieve $1(75 \mu \mathrm{m})$ and sieve $2(38 \mu \mathrm{m})$ followed by preservation in $10 \%$ neutral buffered formalin (NBF) [26]. Adult worms were counted from both contents and digests. Extrapolation from two 1\% or two $5 \%$ aliquots, from sieve 1 and sieve 2 respectively was used for calculating the worm burden.

\begin{abstract}
Abomasal mast cell and eosinophil counts
A section (approximately $2 \mathrm{~cm}^{2}$ ) of abomasal tissue was taken from the midline fold after the recovery of the abomasal contents. The tissue sample was fixed in $10 \%$ NBF and processed in a Sakura Tissue-Tek ${ }^{\circ}$ VIP processor (Clinical Distributor, Dublin, Ireland). The tissue was sectioned using a Leitz 1512 Microtome (GMI Inc, mounted on microscopic slides. These sections were stained using GIEMSA (Merck, UK) and examined using a QImaging colour camera (Nikon, Japan) under a 40X objective. The images were visualised using the program Image-Pro. Mast cells and eosinophils were counted in a field area of $0.023 \mathrm{~mm}^{2}$. A total of 50 such fields were counted per slide and the mean figure was expressed as total number per $0.023 \mathrm{~mm}^{2}$.
\end{abstract}

\section{Mucosal antibody recovery}

Immediately after slaughter, the surface layer together with the mucus epithelial layer of a portion of abomasal fold tissue $\left(\sim 3 \mathrm{~cm}^{2}\right)$, excised from the midline of the dissected abomasum, was removed by scraping with a microscope slide, placed in cryovials and snap frozen in liquid nitrogen followed by storage at $-80{ }^{\circ} \mathrm{C}$ until use. The samples were prepared for antibody recovery according to the method described previously [27]. Briefly, thawed samples in 3 volumes of phosphate buffered saline (PBS) containing $5 \mu \mathrm{g} /$ $\mathrm{mL}$ of protease inhibitor cocktail (Sigma-Aldrich, St Louis, MO, USA) were homogenised using a Retsch $^{\circ}$ tissue lyser (Qiagen, Crawley, UK). After centrifugation of the homogenate at $12000 \mathrm{~g}$ for $30 \mathrm{~min}$ the supernatant was removed and protein concentration determined using the BCA protein assay reagent kit (Pierce, IL, USA). The remaining supernatant was stored at $-20{ }^{\circ} \mathrm{C}$.

\section{IgA ELISA}

Antigen from T. circumcincta L3 was freshly prepared as previously described [26]. ELISA assays to measure IgA in serum or mucosa were performed as described previously [23]. The wells of 96-well polystyrene ELISA plates (BD FalconTM) were coated with $100 \mu \mathrm{L}$ of L3 antigen $(5 \mu \mathrm{g} / \mathrm{mL})$ in carbonate buffer at $\mathrm{pH} 9.6$ and stored at $4{ }^{\circ} \mathrm{C}$ overnight. The plates were washed 4 times using PBS-T (PBS + 1\% Tween). An aliquot of $100 \mu \mathrm{L}$ of either serum sample (diluted 1:50) or mucosal sample (adjusted to $500 \mu \mathrm{g} / \mathrm{mL}$ ) was placed in each well. After plates were washed in PBS 4 times using PBS-T, $100 \mu \mathrm{L}$ of monoclonal mouse anti-ovine IgA (AbD Serotec, UK), diluted 1:50, was added to each well. Plates were then washed 4 times using PBS-T and $100 \mu \mathrm{L}$ of a secondary goat anti-mouse horse-radish peroxidase (HRP) conjugate (Dako Diagnostics, Dublin, Ireland) was added to each well and incubated at $37^{\circ} \mathrm{C}$ for $30 \mathrm{~min}$. After 4 washes with PBS-T, $100 \mu \mathrm{L}$ of chromogen, tetramethylbenzidine (TMB) (Dako Diagnostics, Dublin, Ireland) was added to each well and incubated for $15 \mathrm{~min}$ at room temperature. The reaction was stopped using $100 \mu \mathrm{L}$ of $10 \% 1 \mathrm{M} \mathrm{HCl}$. The AsysTM UVM-240 microplate reader (VWR International, Dublin, Ireland) was used to read the optical density at $450 \mathrm{~nm}$ of each plate. Each plate included 3 wells with PBS (TBSA) instead of plasma as a blank, a single serum sample yielding low levels of nematode specific antibodies as a negative control and a single serum sample yielding high levels of nematode specific antibodies as a positive control.

\section{Pepsinogen and haematology}

Plasma pepsinogen concentration was measured as described previously [28]. Whole blood was used for haematology analysis using an ADVIA2120 haematology system (Bayer Healthcare, Leverkusen, Germany) as per manufacturer's instructions. Neutrophils, eosinophils, monocytes, lymphocytes, basophils, red blood cells (RBC), haemoglobin concentration ( $\mathrm{Hgb})$, platelets and mean corpuscular volume (MCV) were measured.

\section{Statistical analysis}

All data were analysed using Proc MIXED (SAS 2003) to fit a model that had effects for breed, time and their interaction. Observations on eosinophils in abomasal sections and on FEC were log transformed prior to analysis to normalise the residuals. Data on differential white cell counts were subjected to the arcsine transformation prior to analysis. Because of the large variation in mean values among subclasses (day or day-by-breed) for many of the variables 
the heterogeneity of residual variances was tested and accommodated in the mixed model when significant. The results for the $\mathrm{F}$ tests of breed and day effects and their interaction are reported but the main interest is the evidence for breed differences in the pattern of change following experimental infection. Thus, the differences among slaughter days were evaluated on a within-breed basis using Dunnett's test with the lambs slaughtered on day 0 as the control group. Orthogonal polynomials were used to partition the variation between days into single degree of freedom components to describe the pattern of change with time.

\section{Results}

The data on lambs at housing (Table 1) show that there was no difference between the breeds for age or live weight at housing but there was a significant breed effect on $\mathrm{FEC}_{\mathrm{OT}}$ and $\mathrm{FEC}_{\mathrm{NEM}}$ (FEC for Nematodirus battus). There was no evidence for any association between any of the variables in Table 1 and the slaughter group to which lambs were assigned. All lambs that yielded faecal samples were positive for $N$ battus. In the case of "Other trichostrongyles" (excluding S. papillosus), positive counts were recorded for 11/16 Texels and 16/20 Suffolks. It is clear from these data that all lambs had experienced some larval challenge while at pasture. There was no significant difference in carcass weights between the Suffolks $(21.7 \mathrm{~kg})$ and Texels (21.6 kg).

\section{Worm burden and FEC}

The total number of adult worms recovered on days 14, 21 and 35 pi is presented in Figure 1 for each breed. The mean value was higher for Suffolk lambs on all days and the overall breed effect was significant $(P<0.01)$ but there was a significant breed $\mathrm{x}$ day interaction $(P<0.05)$, which reflected the large difference between the breeds at day 14 pi. The FEC values for Texel and Suffolk lambs on day 21 and 35 pi were not significantly different (data not shown).

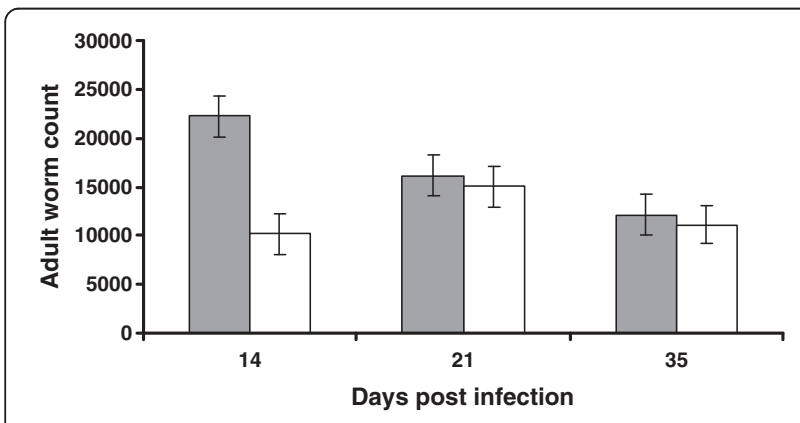

Figure 1 Adult worm burden. Adult worm burden (mean \pm s.e) in the abomasum of Suffolk (shaded bar) and Texel (clear bar) lambs following infection with $3 \times 10^{4} \mathrm{~L} 3$ of $T$. circumcincta.

\section{Pepsinogen}

Pepsinogen concentration over the course of the experiment is summarised in Figure 2. Breed and day effects were highly significant $(P<0.001)$ and there was a highly significant $(P<0.001)$ breed-by-day interaction. The interaction reflects the fact that pepsinogen concentration was significantly elevated relative to control in Suffolk lambs on days 14, 21 and 35 whereas there was no significant change in Texel lambs compared with controls until day 35.

\section{Serum and mucosal IgA}

Levels of serum and mucosal IgA are presented in Figure $3 \mathrm{a}$ and $3 \mathrm{~b}$ respectively. The overall breed effect on serum IgA was not significant but the day effect was significant $(P<0.001)$ with significant quadratic $(P<$ $0.05)$ and cubic components $(P<0.01)$; there was no breed $x$ day interaction. The day effect reflects the fact that levels of serum IgA were highest at day 0 and lower at all subsequent time points in both breeds. Evaluation of the within-breed difference from day 0 showed that serum IgA was significantly lower at all time points except day 14 in Suffolk. While the level of IgA was lower after day 0 in the Texel, this was not statistically significant. The overall breed effect on mucosal IgA was not significant and neither was the breed $\mathrm{x}$ day interaction, but the day effect was highly significant $(P<0.001)$ with a significant quadratic component $(P<0.05)$. Evaluation of the within-breed differences from day 0 showed that the mucosal IgA was significantly $(P<0.01)$ elevated by day 7 pi in Texel lambs but no significant elevation was evident in Suffolk lambs until day 14 pi $(P<0.01)$.

\section{Mast cells and eosinophils in abomasal tissue}

The average number of mast cells in abomasal tissue from Texel and Suffolk lambs over the course of the experiment is presented in Figure 4a. Mast cells were detected in $5 / 6$ Texel lambs (number per lamb $\leq 13$ per $0.023 \mathrm{~mm}^{2}$ of abomasal tissue) on day 0 but only a single mast cell was detected in one Suffolk lamb. Mast cells

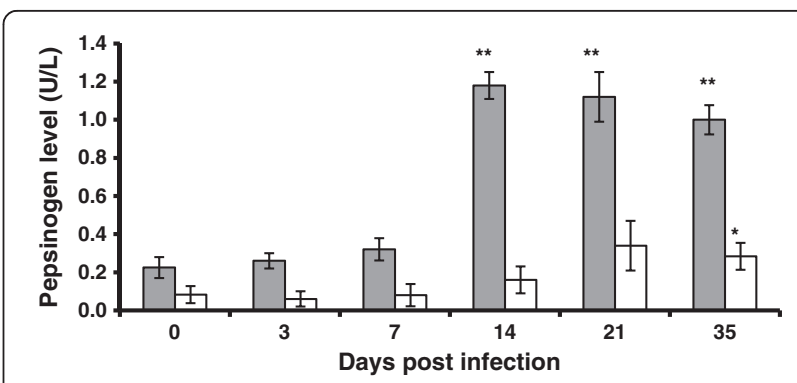

Figure 2 Serum pepsinogen. Mean $( \pm$ s.e.) Serum pepsinogen in Suffolk (shaded bar) and Texel (clear bar) lambs following infection with $3 \times 10^{4} \mathrm{~L} 3$ of $T$. circumcincta. The asterisks on the bars indicate the significance of the difference from the mean at day 0 for each breed $\left.{ }^{*} P<0.05,{ }^{*} P<0.01\right)$. 


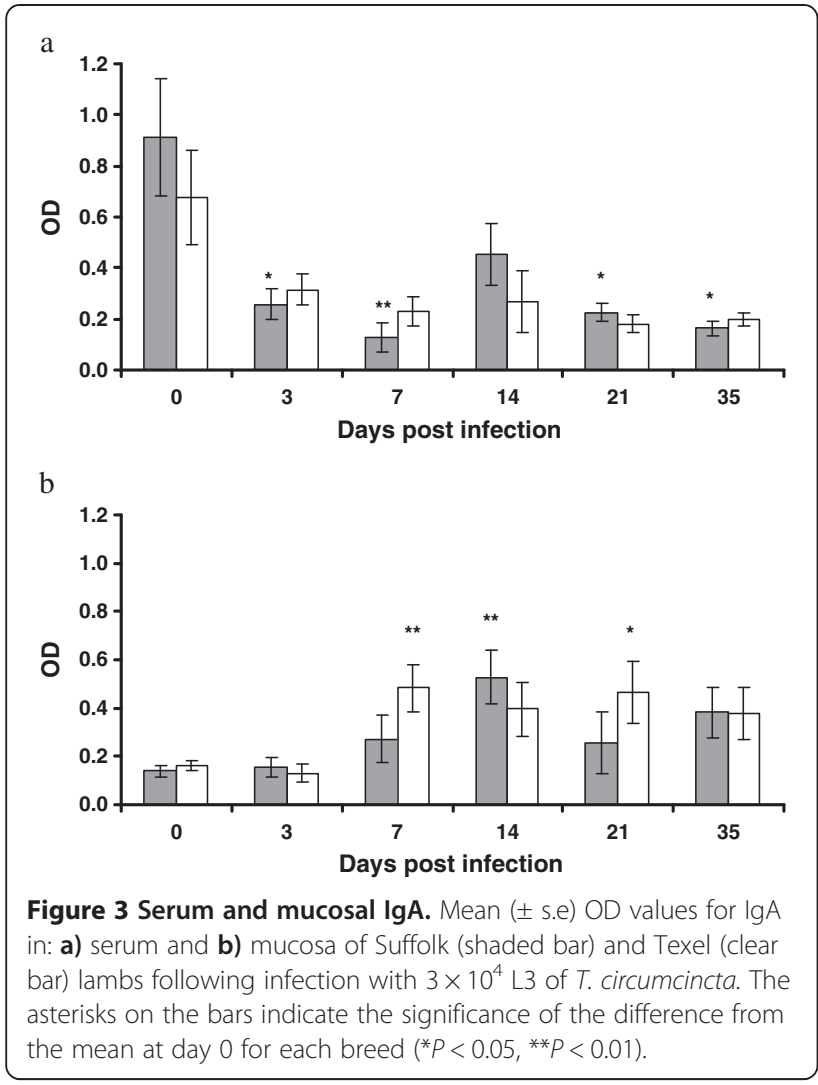

were detected in all animals from day 3 pi onwards and the number peaked at day 14 pi in both breeds; the day effect was significant $(P<0.001)$ and non-linear with an essentially quadratic pattern $(P<0.001)$. Neither breed nor breed-x-day interaction effects were significant. The breed profiles for the number of eosinophils in abomasal tissue over the course of the experiment are shown in Figure 4b. The only occurrence of eosinophils on day 0 was in 3 Texel animals, with low numbers in each case. Neither breed nor breed $x$ day had a significant effect on the number of eosinophils but the day effect was highly significant $(P<0.001)$ with quadratic and cubic components.

\section{Haematology}

The mean values for $\mathrm{Hgb}, \mathrm{MCV}, \mathrm{RBC}$, eosinophils, basophils, lymphocytes, leucocytes, neutrophils, monocytes and platelets are presented in Figure 5. There was a significant $(P<0.05)$ day effect for all these variables except lymphocytes, platelets and MCV. The breed-by-day interaction which was significant for eosinophils $(P<0.05)$ probably reflects the earlier emergence of a significant elevation, relative to day 0 , in the Texel breed. The breed effect was significant for platelets (Texel $>$ Suffolk; $P<0.001$ ), MCV (Texel $>$ Suffolk; $P<0.001$ ) and RBC (Suffolk > Texel; $P<0.001)$.

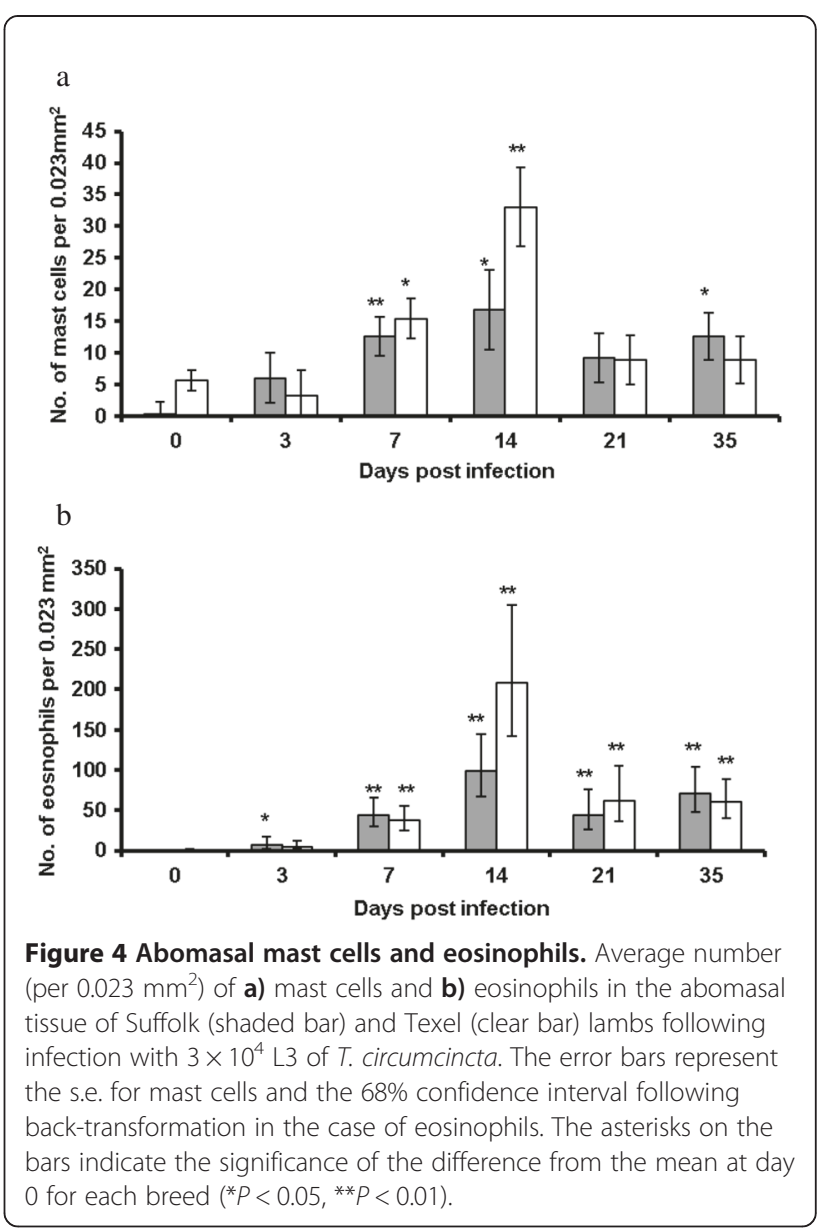

\section{Discussion}

To our knowledge this is the first comparison of the response of Suffolk and Texel lambs to an experimental challenge with $T$. circumcincta. The significant breed difference in worm burden 14 days after artificial infection is consistent with previous observations in this flock on lambs exposed to a natural challenge $[6,24]$. While the lambs on experiment were not naïve to GIN challenge, the worm burden observed to the experimental challenge would suggest there was not a strong carry over immune effect. The results of this study identified a number of underlying humoral and cellular events that can be argued, contribute to, the observed breed difference in resistance to gastrointestinal nematode infection.

A number of haematological variables, namely RBC, MCV and platelets were found to differ significantly between Texel and Suffolk lambs. The higher number of RBC in Suffolk compared to Texel was consistent with previous findings for these breeds [24]. Recognition for an active role of platelets in both innate and adaptive immune response is increasing [29]. Platelets have been associated with a cytotoxic effect on intravascular parasites [30-33]. The major mechanism is thought to 

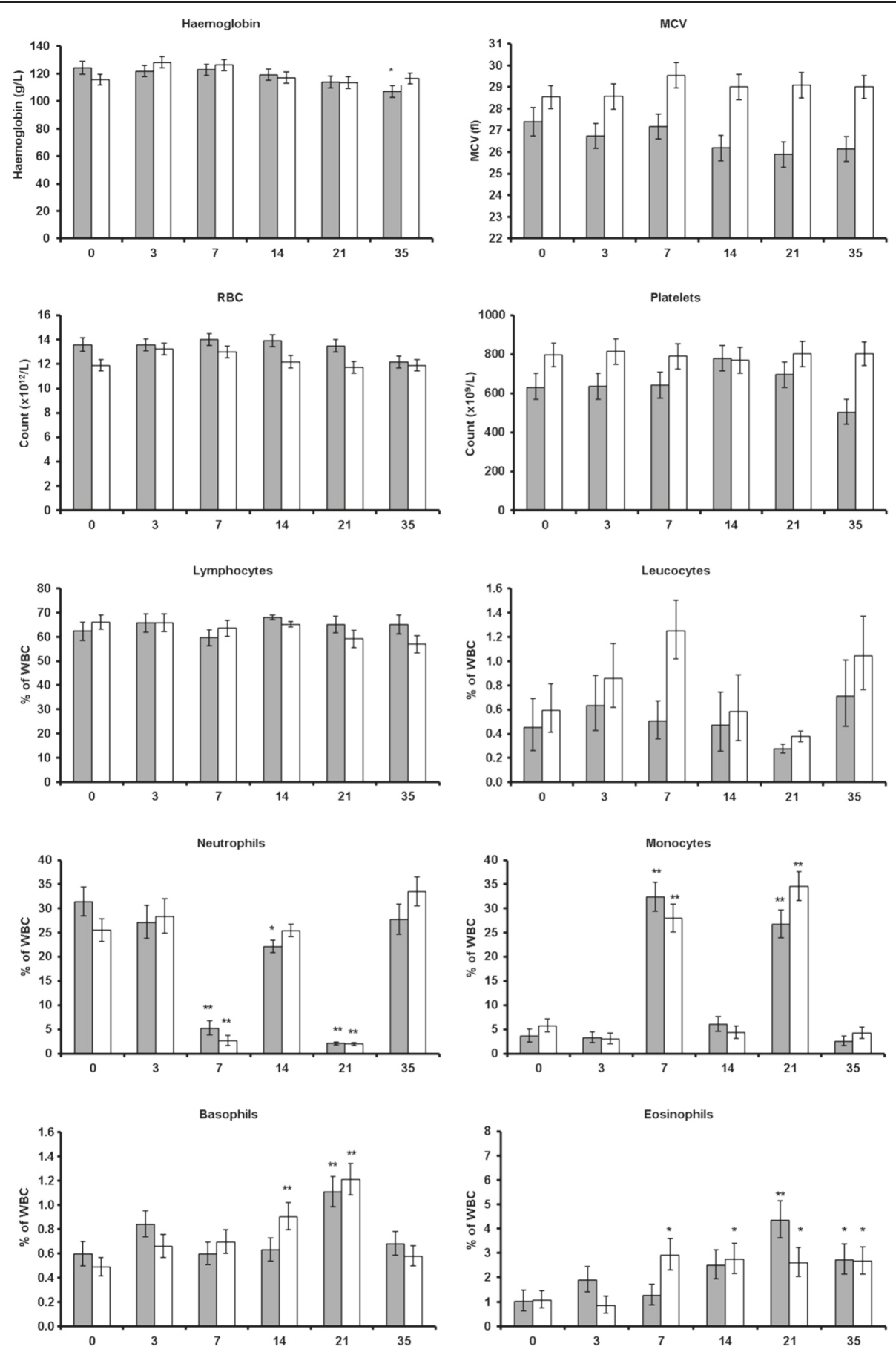

Days post-infection

Figure 5 Hematology variables. Hematological measurements for Suffolk (shaded bar) and Texel (clear bar) lambs following infection with $3 \times 10^{4} L 3$ of T. circumcincta. The error bars for the differential white cell counts represent the $68 \%$ confidence interval following back transformation; in the case of the other variables the s.e. is presented. The asterisks on the bars indicate the significance of the difference from the mean at day 0 for each breed $(* P<0.05$, $\left.{ }^{*} P<0.01\right)$. Percentage means $\%$ of a particular cell type out of total white blood cell.

be the parasitic-specific antibody (IgE) binding to platelets followed by platelet activation which results in platelets releasing contents which are toxic for the parasite [34]. While most of the evidence relates to intravascular parasites, there is some evidence for an active role for platelets in patients with extravascular parasites, in particular to Echinococcus granulosus. While the precise mechanism remains unclear, variables such as 
mean platelet volume, (MPV) platelet factor 4 and $\beta$ thromboglobulin have been used in the demonstration of platelet activation [35,36]. The significantly greater number of platelets in Texels is consistent with that observed in resistant sheep following $T$. circumcincta infection in a previous study [37] and suggests that platelets may contribute to the resistant phenotype of the Texel.

Neutrophils and monocytes account for approximately $20-30 \%$ and $5 \%$ of the blood leucocytes in ruminants respectively. Whilst known for their phagocytic activity, they differ in life span and capacity for cytokine production which is associated with the enhancement of the inflammatory response [38]. Circulating monocytes are precursors to specific macrophages and dendritic cell populations at tissue sites of inflammation and infection. Moreover, a recent study concluded that monocytes have potentially both an innate and antigen presentation function in response to different stages of a blood dwelling helminth parasite [39]. In this study, a reduction in the proportion of neutrophils with corresponding increase in the proportion of monocytes was observed at days 7 and 21 . The timing of monocytosis observed may reflect the response to different antigenic stimuli (larvae at day 7 , adults by day 21 ).

Peripheral and local eosinophils have been associated with resistance to GIN infection [40,41]. An increase in blood eosinophils in resistant lambs following a mono infection of T. circumcincta or $H$. contortus or exposure to a natural challenge has been reported $[6,29,41]$. Based on these findings an active role for eosinophils in determining the resistance characteristics of the Texel to $T$. circumcincta infection was expected. While there was clear evidence for recruitment of eosinophils into the mucosa in both breeds it is not immediately clear why breed differences for mucosal or circulating eosinophils were absent in the present study.

A predominant characteristic of the cellular response to infection was the increase in abomasal mast cell and eosinophil numbers in both breeds following infection. The fact that mast cells were present in Texels on day 0 and absent in Suffolks could contribute to their more immediate response to GIN challenge. It has been reported previously that mast cells and eosinophils play a vital role in controlling worm burden. It is thought that surface-bound IgE antibodies on the parasite rapidly activate mast cells causing granular release, including eosinophil chemotactic factors, leading to the recruitment of eosinophils and basophils. Subsequent degranulation of mast cells, basophils and eosinophils, results in increased intestinal permeability, greater muscular contractility and subsequent parasite expulsion from the gastrointestinal tract $[37,42-45]$. An increase in both cell types in gut mucosa during nematode infection in sheep and cattle has been associated with the development of protective immunity against GIN [38]. A recent study in sheep has demonstrated that the number of abomasal mast cells is negatively correlated with the number of adult $T$. circumcincta [46].

Humoral immunity plays a vital role in resistance to GIN infection $[24,47,48]$ and only successful antigen presentation by MHC class II molecules will stimulate an immune response [49]. The lack of significant breed difference in local mast or eosinophil cell numbers may support the proposition that antigen presentation affecting immunoglobulin affinity/avidity may account for the variation in resistance observed between the breeds [24]. In this study, the concentration of circulating IgA declined in both breeds following infection while a concomitant increase in mucosal concentration was observed. The level of circulating IgA in both breeds prior to the experimental challenge may reflect an immune response to the earlier GIN exposure at pasture (turnout after birth to 6 weeks of age) while the experimental challenge led to increased immunoglobulin receptor expression at the mucosal surface to allow translocation of circulating IgA to the abomasal mucosa which was the site of the experimental challenge. Of interest was the observation that Texel sheep had a more rapid mucosal IgA response in comparison to the Suffolk. The within breed analysis showed a significant increase in mucosal IgA concentration by day 7 pi in Texel but not until day 14 pi in Suffolk. This difference in timing may be very important as parasite specific IgA has been previously associated with reduced worm burden, arrested L4 development $[47,50]$ and reduced worm fecundity and length [42]. The evidence suggests that the Suffolk sheep are slower to generate a local humoral immune response which may impair their ability to control worm development. As it has also been suggested that IgE related mechanisms are implicated in the susceptible phenotype of the Suffolk breed [24] further exploration of the humoral response would be of interest.

In this study, pepsinogen concentration was greatly elevated in Suffolks from day 14 pi onwards. In contrast, pepsinogen concentration in Texels was not significantly elevated until day $35 \mathrm{pi}$ and the increase was quite modest when compared with that observed in Suffolk lambs. These data support previous findings which suggested that GIN infected Suffolks have higher concentrations of circulating pepsinogen than co-grazed Texels [24]. Pepsinogen concentrations greater than $1 \mathrm{U} / \mathrm{L}$ are considered clinically significant [51,52]; the concentration of pepsinogen recorded for Suffolks suggests that these animals suffered much greater abomasal damage than Texels, which may have long-term negative consequences for the Suffolk in terms of ability to manage subsequent challenges and to maintain growth. Support for this hypothesis can be taken from results of a previous study on the effect of contrasting levels of parasite challenge on performance; it was 
found that the Suffolk exhibited a greater growth penalty compared to Texel in the presence of a high level of parasite challenge [53].

In summary, while overall recruitment patterns of mucosal mast cells and eosinophils were similar between breeds, the evidence showed that exposure of infective larvae to mucosal IgA occurred earlier in the Texel breed. It is suggested that this may play a role in the more effective control of worm burden in the Texel. The Suffolk breed had significantly higher worm burden at day 14 and elevated pepsinogen concentration from day 14 onwards. It is speculated that the greater damage to the mucosa observed in the Suffolk would render Suffolk lambs more susceptible to the on-going larval challenge that would occur under normal grazing conditions and so contribute to the susceptible phenotype of the Suffolk breed.

\section{Competing interests}

The authors declare that they have no competing interests.

\section{Authors' contributions}

All authors participated in sample collection. AG and BG carried out worm burden and FEC analysis. AMA, SS, AM and KT carried out haematology, serum immunoglobulin, mast cell and eosinophil analysis. TS, JPH, OMK and BG participated in experiment design, sample collection and data analysis. All authors participated in manuscript preparation and read and approved the final manuscript

\section{Acknowledgements}

The authors gratefully acknowledge the assistance of technical and farm staff at the Teagasc Research Centre, Athenry for animal care. This work was funded under the Teagasc Walsh Fellowship scheme.

\section{Author details}

${ }^{1}$ Veterinary Sciences Centre, University College Dublin, Belfield, Dublin 4 Ireland. ${ }^{2}$ Animal \& Grassland Research and Innovation Centre, Teagasc, Athenry, Co. Galway, Ireland. ${ }^{3}$ AGRIC, Teagasc, Grange, Dusany, Co. Meath., Ireland.

\section{Received: 18 December 2013 Accepted: 11 December 2014}

Published online: 17 February 2015

\section{References}

1. Park M, Strain S, Wallace D (1998) The processes influencing the distribution of parasitic nematodes among naturally infected lambs. Parasitology 117:165-171

2. Morgan E, van Dijk J (2012) Climate and the epidemiology of gastrointestinal nematode infections of sheep in Europe. Vet Parasitol 189:8-14

3. Coop RL, Kyriazakis I (2001) Influence of host nutrition on the development and consequences of nematode parasitism in ruminants. Trends Parasitol 17:325-330

4. Alberti E, Zanzani S, Ferrari N, Bruni G, Manfredi M (2012) Effects of gastrointestinal nematodes on milk productivity in three dairy goat breeds. Small Rumin Res 106:S12-S17

5. Papadopoulos E, Gallidis E, Ptochos S (2012) Anthelmintic resistance in sheep in Europe: a selected review. Vet Parasitol 189:85-88

6. Good B, Hanrahan J, Crowley B, Mulcahy G (2006) Texel sheep are more resistant to natural nematode challenge than Suffolk sheep based on faecal egg count and nematode burden. Vet Parasitol 136:317-327

7. Mugambi J, Bain R, Wanyangu S, Ihiga M, Duncan J, Murray M, Stear M (1997) Resistance of four sheep breeds to natural and subsequent artificial Haemonchus contortus infection. Vet Parasitol 69:265-273

8. Mugambi J, Wanyangu S, Bain R, Owango M (1996) Response of Dorper and Red Maasai lambs to trickle Haemonchus contortus infections. Res Vet Sci 61:218-221
9. Amarante AFT, Bricarello P, Rocha R, Gennari S (2004) Resistance of Santa Ines, Suffolk and lle de France sheep to naturally acquired gastrointestinal nematode infections. Vet Parasitol 120:91-106

10. Li RW, Choudhary RK, Capuco AV, Urban JF, Jr (2012) Exploring the host transcriptome for mechanisms underlying protective immunity and resistance to nematode infections in ruminants. Vet Parasitol 109:1-11

11. Stear M, Strain S, Bishop S (1999) Mechanisms underlying resistance to nematode infection. Int J Parasitol 29:51-56

12. Sayers G, Sweeney $T$ (2005) Gastrointestinal nematode infection in sheep a review of the alternatives to anthelmintics in parasite control. Anim Health Res Rev 6:159-171

13. Stear MJ, Bishop SC, Duncan JL, McKellar QA, Murray M (1995) The repeatability of faecal egg counts, peripheral eosinophil counts, and plasma pepsinogen concentrations during deliberate infections with Ostertagia circumcincta. Int J Parasitol 25:375-380

14. Cringoli G, Rinaldi L, Veneziano V, Pennacchio S, Morgoglione ME, Santaniello M, Schioppi M, Fedele V (2008) Gastrointestinal strongyle faecal egg count in goats: circadian rhythm and relationship with worm burden. Vet Res Commun 32:191-193

15. McEwan JC. Worm FEC-Breeding sheep resistant to roundworm infection, Breeders Manual AgResearch, New Zealand Pastoral Agricultural Research Institute Limited. Invermay; 1994. 33

16. Villanua D, Perez-Rodriguez L, Gortazar C, Hofle U, Vinuela J (2006) Avoiding bias in parasite excretion estimates: the effect of sampling time and type of faeces. Parasitology 133:251-259

17. Cringoli G, Rinaldi L, Veneziano V, Capelli G, Scala A (2004) The influence of flotation solution, sample dilution and the choice of McMaster slide area (volume) on the reliability of the McMaster technique in estimating the faecal egg counts of gastrointestinal strongyles and Dicrocoelium dendriticum in sheep. Vet Parasitol 123:121-131

18. Rinaldi L, Coles G, Maurelli M, Musella V, Cringoli G (2011) Calibration and diagnostic accuracy of simple flotation, McMaster and FLOTAC for parasite egg counts in sheep. Vet Parasitol 177:345-352

19. Mes TH (2003) Technical variability and required sample size of helminth egg isolation procedures. Vet Parasitol 115:311-320

20. Vidyashankar A, Hanlon B, Kaplan R (2012) Statistical and biological considerations in evaluating drug efficacy in equine strongyle parasites using fecal egg count data. Vet Parasitol 185:45-56

21. Stear M, Reid S, Gettinby G (1996) The likelihood of detecting differences between groups of sheep following deliberate infection with Ostertagia circumcincta. Int J Parasitol 26:657-660

22. Allen JE, Maizels RM (2011) Diversity and dialogue in immunity to helminths. Nat Rev Immunol 11:375-388

23. Stear M, Bairden K, McKeller Q, Scott I, Strain S, Bishop S (1999) The relationship between the number and size of nematodes in the abomasum and the concentration of pepsinogen in ovine plasma. Res Vet Sci 67:89-92

24. Sayers G, Good B, Hanrahan J, O'Donovan J, Mulcahy G, Sweeney T (2008) Breed differences in mucosal and systemic antibody response to nematode infection in sheep: an important role for lgE? Parasitology 135:71-80

25. Anon (1986) Modified McMaster Method Improved In Ministry of Agriculture Fisheries Food: Manual of Veterinary Parasitological Laboratory Techniques (Reference Book; 418). Her Majesty's Stationery Office (HMSO), London, pp 12-13

26. Eysker M, Kooyman FN (1993) Notes on necropsy and herbage processing techniques for gastrointestinal nematodes of ruminants. Vet Parasitol 46:205-213

27. Sinski E, Bairden K, Duncan J, Eisler M, Holmes P, McKellar Q, Murray M, Stear M (1995) Local and plasma antibody responses to the parasitic larval stages of the abomasal nematode Ostertagia circumcincta. Vet Parasitol 59:107-118

28. Ross J, Purcell D, Dow C, Todd J (1967) Experimental infections of calves with Trichostrongylus axei; the course and development of infection and lesions in low level infections. Res Vet Sci 8:201-206

29. Semple JW, Freedman J (2010) Platelets and innate immunity. Cell Mol Life Sci 67:499-511

30. Polack B, Peyron F, Auriault C (1991) Platelet cytotoxicity against parasites. Nouv Rev Fr Hematol 33:317-322

31. Shaw KT, Mawji Y, Stevenson MM, Kongshavn PA (1991) Cells within the vascular system capable of mediating trypanocidal activity in vitro. Infect Immun 59:3143-3150 
32. McMorran BJ, Marshall VM, de Graaf C, Drysdale KE, Shabbar M, Smyth GK, Corbin JE, Alexander WS, Foote SJ (2009) Platelets kill intraerythrocytic malarial parasites and mediate survival to infection. Science 323:797-800

33. Da'dara AA, Skelly PJ (2014) Schistosomes versus platelets. Thromb Res 134:1176-1181

34. Clemetson KJ (2011) The role of platelets in defence against pathogens. Hamostaseologie 31:264-268

35. Matowicka-Karna J, Kemona H, Dymicka-Piekarska V, Butkiewicz A (2005) [The secretory activity of blood platelets $\beta$-thromboglobulin and platelet factor 4 in echinococcosis]. Polski Merkuriusz Lekarski 19:172-174 (in Polish)

36. Sit M, Aktaş G, Yilmaz EE, Hakyemez IN, Alçelik A, Küçükbayrak A (2013) Platelet parameters in hepatic hydatid cysts. Int J Inflamm 2013:593273

37. Hassan M, Good B, Hanrahan JP, Campion D, Sayers G, Mulcahy G, Sweeney $T$ (2011) The dynamic influence of the DRB1*1101 allele on the resistance of sheep to experimental Teladorsagia circumcincta infection. Vet Res 42:46

38. Tizzard IR (2000) Veterinary Immunology, 6th edition. WB Saunders Company, Philadelphia, Pennsylvania, p 18

39. Turner JD, Bourke CD, Meurs L, Mbow M, Dièye TN, Mboup S, Polman K, Mountford AP (2014) Circulating CD14brightCD16+ 'Intermediate' monocytes exhibit enhanced parasite pattern recognition in human helminth infection. PLoS Neg Trop Dis 8:e2817

40. Stear M, Henderson N, Kerr A, McKellar QA, Mitchell S, Seeley C, Bishop SC (2002) Eosinophilia as a marker of resistance to Teladorsagia circumcincta in Scottish Blackface lambs. Parasitology 124:553-560

41. Shakya KP, Miller JE, Lomax LG, Burnett DD (2011) Evaluation of immune response to artificial infections of Haemonchus contortus in Gulf Coast Native compared with Suffolk lambs. Vet Parasitol 181:239-247

42. Stear M, Bishop S, Doligalska M, Duncan J, Holmes P, Irvine J, McCririe L, McKellar Q, Sinski E, Murray M (2007) Regulation of egg production, worm burden, worm length and worm fecundity by host responses in sheep infected with Ostertagia circumcincta. Parasite Immunol 17:643-652

43. McDermott JR, Bartram RE, Knight PA, Miller HRP, Garrod DR, Grencis RK (2003) Mast cells disrupt epithelial barrier function during enteric nematode infection. Proc Natl Acad Sci U S A 100:7761-7766

44. Seaton DS, Jackson F, Smith WD, Angus KW (1989) Development of immunity to incoming radiolabelled larvae in lambs continuously infected with Ostertagia circumcincta. Res Vet Sci 46:241-246

45. Balic A, Bowles VM, Meeusen EN (2000) The immunobiology of gastrointestinal nematode infections in ruminants. Adv Parasitol 45:181-24

46. Williams AR (2012) Short communication: some observations on the role of bradykinin in immunity to Teladorsagia circumcincta in sheep. J Parasitol Res 2012:569287

47. Halliday A, Routledge C, Smith S, Matthews J, Smith W (2007) Parasite loss and inhibited development of Teladorsagia circumcincta in relation to the kinetics of the local IgA response in sheep. Parasite Immunol 29:425-434

48. Henderson N, Stear M (2006) Eosinophil and IgA responses in sheep infected with Teladorsagia circumcincta. Vet Immunol Immunopath 112:62-66

49. Neefjes J, Jongsma ML, Paul P, Bakke O (2011) Towards a systems understanding of MHC class I and MHC class II antigen presentation. Nat Rev Immunol 11:823-836

50. Stear M, Bairden K, Innocent G, Mitchell S, Strain S, Bishop S (2004) The relationship between IgA activity against 4th-stage larvae and density dependent effects on the number of 4th-stage larvae of Teladorsagia circumcincta in naturally infected sheep. Parasitology 129:363-369

51. Armour J, Bruce R (1974) Inhibited development in Ostertagia ostertagia infections - a diapause phenomenon in a nematode. Parasitology 69:161-174

52. Anderson N, Armour J, Jarrett WFH, Jennings FW, Ritchie JSD, Urquhart GM (1965) A field study of parasitic gastroenteritis in cattle. Vet Rec 77:1196-1204

53. Hanrahan JP, Good B (2010) Performance of Suffolk and Texel sheep grazing sheep pastures that presented contrasting levels of parasite challenge. Adv Anim Biosci 1:6

\section{Submit your next manuscript to BioMed Central and take full advantage of:}

- Convenient online submission

- Thorough peer review

- No space constraints or color figure charges

- Immediate publication on acceptance

- Inclusion in PubMed, CAS, Scopus and Google Scholar

- Research which is freely available for redistribution

Submit your manuscript at www.biomedcentral.com/submit 